\title{
Optimization of Hull Structure and Noise Control Measures for Noise in Accommodation Space
}

\author{
by Takumi Ozawa*, Member \\ Taiki Tsukada** \\ Shinji Abe ${ }^{* * *}$
}

\author{
Masaru Hirakata*, Member \\ Shohei Suda** \\ Toshiyuki Takahashi ${ }^{* * *}$
}

\begin{abstract}
Summary
International Maritime Organization Maritime Safety Committee, at its 91 session on November 2012, adopted draft amendment to SOLAS regulation II-1/3-12, which changes the Code on noise levels on board ships from non-mandatory to mandatory. This paper provides optimizing process for ship noise in the accommodation space on the basis of results of noise analysis using SEA models of a certain oil tanker of 6,500 kiloliters actually constructed by a shipyard. In this regard, the authors identified how hull structure should be arranged and how noise control measures should be applied in order to reduce the target ship's noise levels efficiently by using generally useful optimizing process.
\end{abstract}

\section{Introduction}

International Maritime Organization (IMO) Maritime Safety Committee (MSC), at its 91 session on November 2012, adopted draft amendment to the Code on noise levels on board ships ${ }^{1)}$ and SOLAS regulation II-1/3-12, which changes the Code from non-mandatory to mandatory, by MSC.337(91) and MSC.338(91).

The Code also applies to domestic vessels. The domestic vessels contain tankers of 6,500 kiloliters at a high rate. However it is said that it is difficult for small commercial ship such as these vessels to comply with the Code due to limited structural design. Furthermore, superstructure mass, stability and cost should be also considered when considering noise countermeasure, such as hull structure arrangements and noise control measures in the accommodation space. However, the method for designing ships considering these factors at the same time is still under developing.

This paper provides optimizing process for ship noise to support ship designers by operating noise analysis in the accommodation space using Statistical Energy Analysis (SEA). In this regard, the ship to be optimized is based on plans and noise measurement of a certain oil tanker of 6,500 kiloliters actually constructed by a shipyard (target ship). In addition, superstructure mass and cost were used as constrains or objective functions.

\footnotetext{
* National Institute of Maritime, Port and Aviation Technology

** ESI Japan, Ltd.

*** Japan Railway Construction, Transport and Technology Agency

**** Shin kurushima dockyard Co., Ltd.
}

Received 18 September 2018

\section{Target ship and SEA}

\section{1 Summary of the target ship}

The joiner plan of the target ship is shown in Fig. 1. In this plan, thick lines, black lines, gray lines and double lines indicate outer steel walls, inner steel walls, partition walls (cassette panels) and Engine Casing (EC) walls respectively as shown in Fig. 1(d). The EC is separated from the accommodation space on $\mathrm{C}$ and $\mathrm{B}$ decks. In addition, the ship consists of seven decks, i.e. three decks in the machinery space and four decks in the accommodation space. The main engine is located at the bottom deck and the generator engines at 2 nd deck.

\section{2 SEA}

\section{2. 1 Summary of SEA}

The SEA is a system with elements that calculates each element's energy with formulating power balance between elements of the model. In SEA, vibration levels of structural elements and sound pressure levels of acoustic elements are calculated from each element's energy value. It is said that SEA is effective compared with FEM, in particular, in a high frequency range. Fig. 2 shows a SEA model consisted of two elements. Here, in the element 1 , external power input is $P_{i n, 1}$, power loss in the element, such as transformation to thermal energy, is $P_{\text {diss, }, 1}$, and power flow from element 1 to element 2 is $P_{\text {coupling,12. }} P_{\text {diss }, 1}$ and $P_{\text {coupling, } 12}$ are expressed by the following Eq. (1) and (2) respectively.

$$
\begin{gathered}
P_{\text {diss }, 1}=\omega \eta_{1} E_{1} \\
P_{\text {coupling, } 12}=\omega n_{1} \eta_{12}\left(E_{1} / n_{1}-E_{2} / n_{2}\right)
\end{gathered}
$$

where $\omega$ is angular velocity, $n_{1}$ and $n_{2}$ are modal density of the element 1 and 2 respectively, $\eta_{1}$ is a damping loss factor, $E_{1}$ and $E_{2}$ are energy in the element 1 and 2 respectively and $\eta_{12}$ is a coupling loss factor, which is obtained from structural and 
material properties of each element. In addition, for $P_{i n, 1}, P_{\text {diss }, 1}$

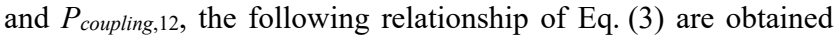
on the basis of law of the conservation of energy.

$$
P_{i n, 1}=P_{\text {diss }, 1}+P_{\text {coupling, } 12}
$$

Eq. (4) is also established, taking into account that the similar relationship is established in the element 2.

$$
\left\langle\begin{array}{l}
P_{i n, 1} \\
P_{i n, 2}
\end{array}\right\rangle=\omega\left[\begin{array}{cc}
\eta_{1}+\eta_{12} & -\eta_{12} n_{1} / n_{2} \\
-\eta_{21} n_{2} / n_{1} & \eta_{2}+\eta_{21}
\end{array}\right]\left\langle\begin{array}{c}
E_{1} \\
E_{2}
\end{array}\right\rangle
$$

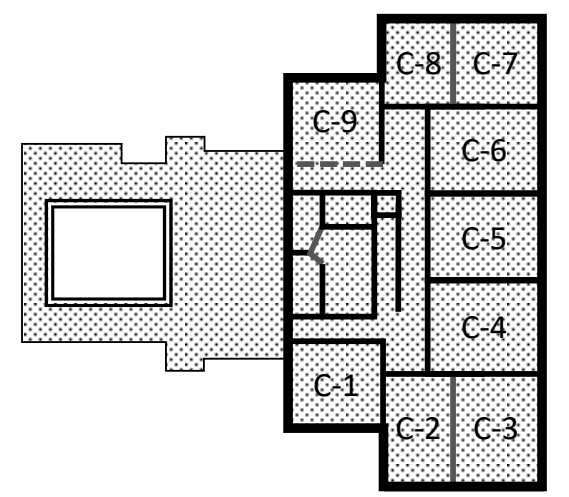

(a) $\mathrm{C}$ deck

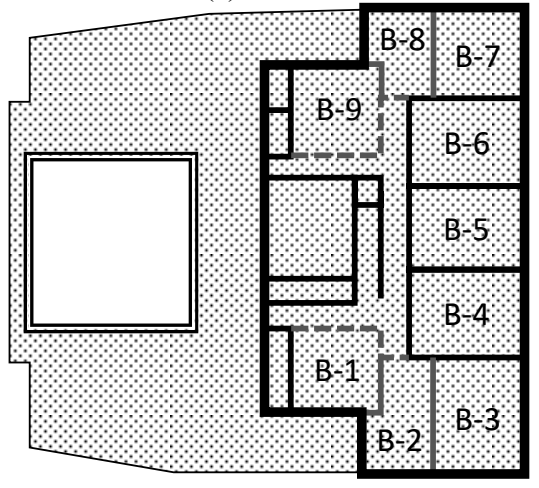

(b) B deck

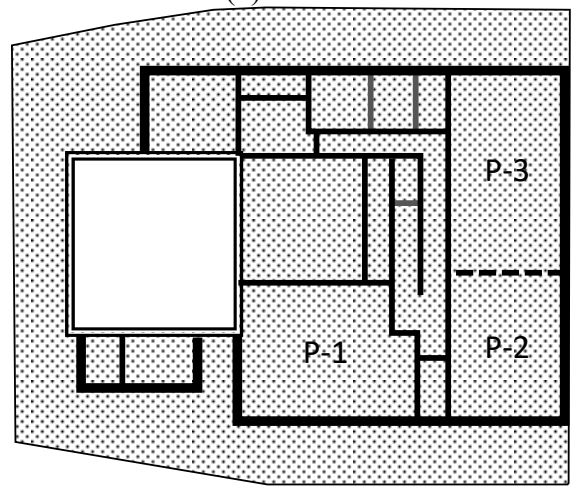

(c) P deck

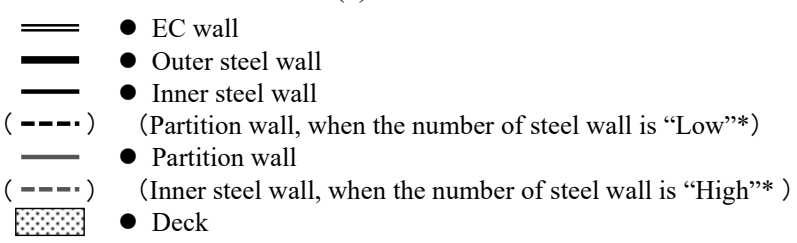

* Referred to Table 2

(d) Symbol

Fig. 1 Joiner Plan
A more general formula than Eq. (4) is expressed in Eq. (5). In Eq. (5), the number of elements is not limited to two unlike Eq. (4).

$$
\left\langle P_{i n}\right\rangle=\omega[\eta]\langle E\rangle
$$

Determining one of the power input or energy in element, the other is obtained for each element in Eq. (5). Namely, Eq. (5) is the governing equation of SEA.

\section{2. 2 SEA model of the target ship}

The SEA model of the target ship is shown in Fig. 3. Decks, walls and ceilings are modeled with structural elements and air are modeled with acoustic elements. In this paper, $\mathrm{VAONE}^{2}$, which is software for noise and vibration analysis, was used as a preprocessor and a solver. It was assumed that noise sources are only the ship's main engine and generator engine. In this regard, noise and vibration measurements on board were used in corresponding elements of the SEA model as boundary conditions. Sources level of each engine are shown in Fig. 4. In the SEA model, noise and vibration levels were calculated for each $1 / 3$ octave band center frequency from $63 \mathrm{~Hz}$ to $8,000 \mathrm{~Hz}$.

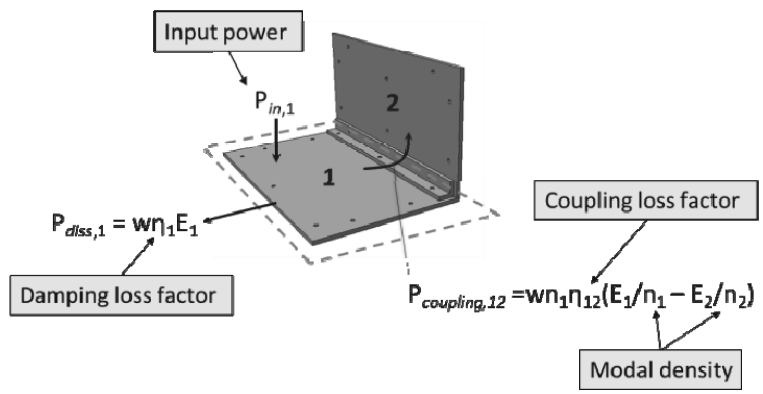

Fig. 2 SEA model consisting of two elements

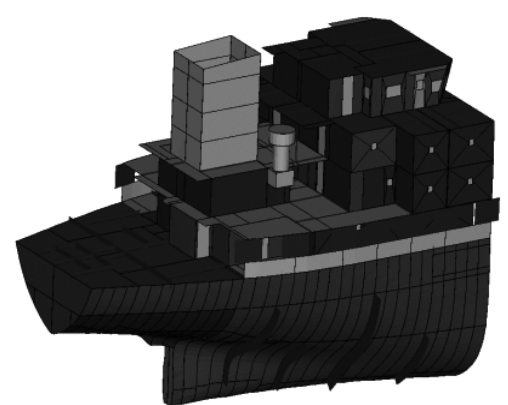

(a) Exterior

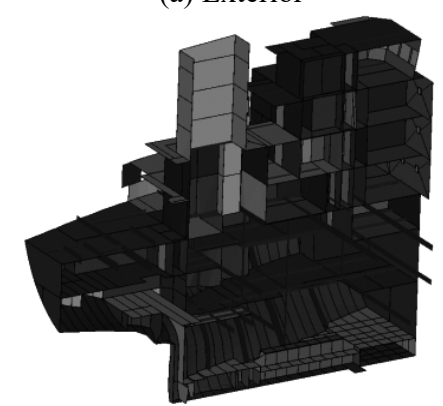

(b) Interior

Fig. 3 SEA model of the target ship 


\section{2. 3 Results of noise levels measured in the target ship and} of noise levels calculated using the SEA model

Noise criteria, measured noise in the target ship and noise calculated using the SEA model in overall value (OA) are shown in Table 1. In addition, the frequency spectrum in P-1 is shown in Fig. 5 in order to show an example of the frequency spectrum of noise level. Calculated noise are obtained from acoustic element energy of each room. Since the ship is lower than $10,000 \mathrm{GT}$, noise criteria of private rooms, which are located on $\mathrm{C}$ and $\mathrm{B}$ deck, are $60 \mathrm{~dB}$ and that of public rooms, which are located on $\mathrm{P}$ deck, is $65 \mathrm{~dB}$. In the target ship, $\mathrm{C}-1$ corresponds to a dry room which is normally unoccupied space. Therefore, its criterion is $90 \mathrm{~dB}$.

\section{Optimization}

\section{1 Summary}

In this paper, optimizations were carried out by two steps, i.e. a baseline design phase and an interior design phase. In the baseline design phase, design parameters are the hull structure arrangements, such as the structural size, the $\mathrm{C}$ deck arrangement and the number of steel walls. In addition, its constraint is superstructure mass increment and its objective function is the probability that actual noise is not more than noise criteria in all rooms (total probability). Authors decided the design parameters and constraint taking into account of ship designers' perspective. In the interior design phase, design parameters are adoptions of each noise control measure and objective functions are the total cost and the total probability. Namely, multi-objective optimization was carried out. The hull structure at the interior design phase is the optimal solution at the baseline design phase.

In addition to SEA, Response Surface (RS) methodology was used for determining ship noise. In this paper, calculated noise means SEA result, estimated noise means RS result and actual noise means noise assumed when built with considering modeling error and disturbance.

\section{2 Baseline design phase}

\section{2. 1 Design parameters}

The relationship between levels and actual values of each design parameter at the baseline design phase is shown in Table 2. Furthermore, the levels of the target ship are shown in Table 3. In this paper, the SEA model, of which design parameters are the same as listed in Table 3, is referred as "original model". When the number of steel wall is "Low", steel walls located at the black dotted line in Fig. 1 are replaced with cassette panels, and is "High", cassette panels located at the gray dotted line in Fig. 1 are replaced with steel walls. When $\mathrm{C}$ deck arrangement is "Separated", the EC and the accommodation space on C deck are completely separated by means of deleting a part of the weather deck as shown in Fig. 6. In this study, deck height and each thickness were regarded as discrete parameters having only one value out of the three levels in this paper, taking into account of the simplification to the optimization and the limitation of steel plate's thickness distributed.

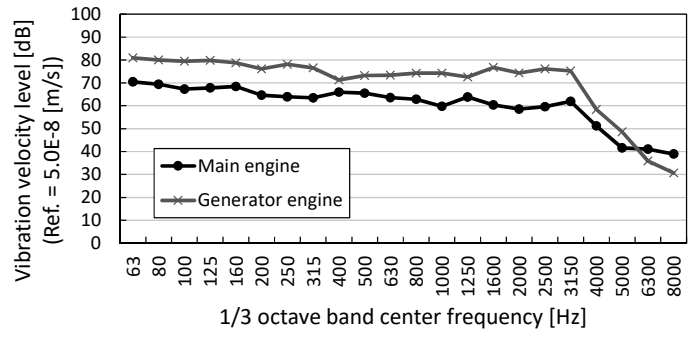

(a) Vibration velocity levels

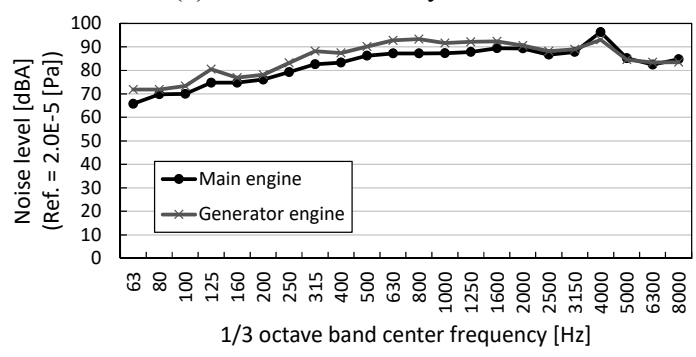

(b) Noise levels

Fig. 4 Sources level of each engine

Table 1 Noise level for each room in OA

\begin{tabular}{|c|c|c|c|c|}
\hline Room name & $\begin{array}{c}\text { Area } \\
{\left[\mathrm{m}^{2}\right]}\end{array}$ & $\begin{array}{c}\text { Criterion } \\
{[\mathrm{dB}]}\end{array}$ & $\begin{array}{c}\text { Measurement } \\
{[\mathrm{dB}]}\end{array}$ & $\begin{array}{c}\text { Calculated } \\
\text { noise }[\mathrm{dB}]\end{array}$ \\
\hline \hline C-1 & 9.6 & 90 & 52.3 & 50.5 \\
\hline C-2 & 9.6 & 60 & 54.6 & 46.0 \\
\hline C-3 & 12.8 & 60 & 53.2 & 45.7 \\
\hline C-4 & 12.0 & 60 & 47.5 & 47.4 \\
\hline C-5 & 12.0 & 60 & 46.9 & 47.4 \\
\hline C-6 & 12.0 & 60 & 47.6 & 48.3 \\
\hline C-7 & 9.3 & 60 & 51.4 & 47.4 \\
\hline C-8 & 7.5 & 60 & 54.4 & 50.2 \\
\hline C-9 & 9.6 & 60 & 53.5 & 52.2 \\
\hline B-1 & 9.0 & 60 & 53.3 & 55.4 \\
\hline B-2 & 8.2 & 60 & 57.3 & 54.0 \\
\hline B-3 & 12.8 & 60 & 53.9 & 52.8 \\
\hline B-4 & 12.0 & 60 & 49.3 & 53.6 \\
\hline B-5 & 12.0 & 60 & 50.5 & 53.5 \\
\hline B-6 & 12.0 & 60 & 49.3 & 54.1 \\
\hline B-7 & 9.3 & 60 & 56.2 & 53.9 \\
\hline B-8 & 6.8 & 60 & 58.1 & 57.0 \\
\hline B-9 & 9.0 & 60 & 54.4 & 58.8 \\
\hline P-1 & 28.0 & 65 & 64.1 & 65.3 \\
\hline P-2 & 20.0 & 65 & 59.9 & 58.7 \\
\hline P-3 & 28.0 & 65 & 58.7 & 60.7 \\
\hline & & & & \\
\hline
\end{tabular}

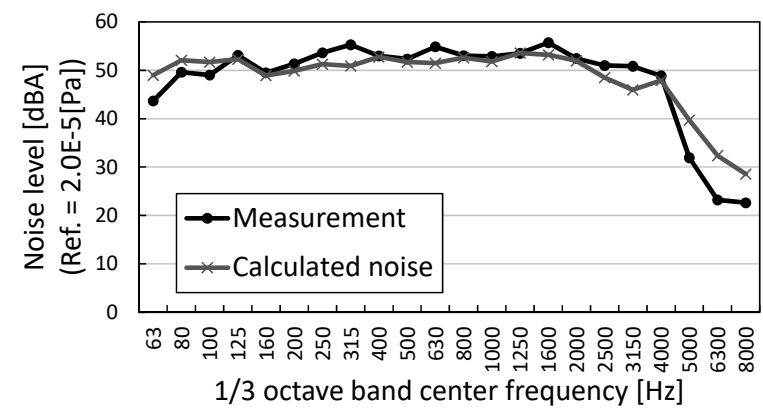

Fig. 5 Frequency spectrum of noise level in P-1 


\section{2. 2 Objective function and constraint}

In the baseline design phase, the objective function is the total probability and the constraint is the superstructure mass increment compared with that of the original model. As mentioned in paragraph 3.1 , the total probability $(P)$ is the probability that actual noise levels are not more than noise criteria in all rooms, and it is given as Eq. (6).

$$
P=\prod_{i} P_{i}
$$

where $P_{i}$ is the probability that actual noise is not more than the noise criterion in each room (partial probability). If actual noise is regarded as the same as calculated/estimated noise by using $\mathrm{SEA} / \mathrm{RS}, P_{i}$ is only a value of 1 or 0 because SEA is based on the determinism. However, calculated/estimated noise are not always equal to actual noise because of modeling errors and disturbances (e.g. noise from outside, beat noise of furniture and ventilation noise) as shown in Table 1. In this paper, in order to evaluate actual noise probabilistically, OA of actual noise was assumed to be a normal distribution. In this regard, it was assumed that its average value $\left(\mu_{i}\right)$ is OA of calculated/estimated noise, and its standard deviation $\left(\sigma_{i}\right)$ is $1.5 \mathrm{~dB}$ on the basis of noise measurement and analysis experience. However, if some noise control measures are applied in the interior design phase, $\sigma_{i}$ was assumed to be $2.1 \mathrm{~dB}(1.5 \times \sqrt{2})$. Therefore, $P_{i}$ is given as Eq. (7).

$$
P_{i}=\frac{1}{2}\left(1+\operatorname{erf} \frac{L_{i}-\mu_{i}}{\sqrt{2 \sigma_{i}^{2}}}\right)
$$

where erf is the Gauss error function and $L_{i}$ is the noise criterion.

In the baseline design phase, the superstructure mass increment, which affects ship's stability and load capacity, is used as a constraint. Since mass increment of cassette panels and equipment is much lower than that of steel plates, the superstructure mass was only taken into account steel mass used in walls and decks but not mass of cassette panels and equipment. The superstructure mass of the original model is 79.8 ton. A frequency distribution of the superstructure mass for all combination of design parameters is shown in Fig. 7.

Table 2 Design parameter and its value for each level

\begin{tabular}{|c|c|c|c|c|c|}
\hline $\begin{array}{c}\text { Design } \\
\text { parameter }\end{array}$ & \multirow{2}{*}{ Symbol } & Unit & \multicolumn{3}{|c|}{ Level } \\
\cline { 4 - 6 } & $h$ & $\mathrm{~m}$ & 2.55 & 2.60 & 2.65 \\
\hline \hline Deck height & $h$ & $\mathrm{~mm}$ & 6 & 8 & 10 \\
\hline $\begin{array}{c}\text { Outer wall } \\
\text { thickness }\end{array}$ & $t_{O}$ & $\mathrm{~mm}$ & 6 & 8 & 10 \\
\hline $\begin{array}{c}\text { Inner wall } \\
\text { thickness }\end{array}$ & $t_{I}$ & $\mathrm{~mm}$ & 6 & 8 & 10 \\
\hline $\begin{array}{c}\text { Deck plate } \\
\text { thickness }\end{array}$ & $t_{D}$ & $\mathrm{~mm}$ & 6 & 8 & 10 \\
\hline $\begin{array}{c}\text { EC wall } \\
\text { thickness }\end{array}$ & $t_{E}$ & $\mathrm{~mm}$ & Low & Original & High \\
\hline $\begin{array}{c}\text { Number of } \\
\text { steel wall }\end{array}$ & $N_{I}$ & $\searrow$ & Original & Separated \\
\hline $\begin{array}{c}\text { C deck } \\
\text { arrangement }\end{array}$ & $C$ & $\searrow$ & & & \\
\hline
\end{tabular}

\section{2.3 Design of experiment (DOE) methodology and RS}

\section{2.3. 1 Summary}

Comparatively correct optimum solution can be obtained by means of calculating noise levels using SEA for all design parameters' combinations. However, the number of all combinations, i.e. $1458\left(3^{6} \times 2\right)$, makes calculating noise levels for all design parameters' combinations difficult, taking into account time for modeling, analysis and evaluation of the SEA model. Therefore, in this paper, only design parameters' combinations selected using DOE were modeled, analyzed and evaluated using SEA. The RS was developed with the calculation results in the selected combinations, and noise levels in any combinations were estimated using RS.

\section{2. 3. 2 DOE}

In this paper, the authors used D-optimal design as DOE, taking into account of RS. D-optimal design is one of the DOE which searches the combination maximizing a determinant of the moment matrix (M). The moment matrix is given as Eq. (8).

$$
\mathbf{M}=\frac{\mathbf{X}^{\mathbf{T}} \mathbf{X}}{n}
$$

where $n$ is the number of calculating points, and in this paper, $n$ is 16 obtained by adding 1 to the number of the design parameters and doubling it. Regarding the matrix $\mathbf{X}$, the number of row is $n$ and that of column is 8 obtained by adding 1 to the number of the design parameters. In addition, the matrix contains levels in each calculation points for each row and in each design parameters for each column except for the first one. All of the value at the first column is 1 . In this paper, the combination of calculation points that maximize the determinant of the moment matrix was searched with $\mathrm{RSMaker}^{3}$. The result of calculation points is shown in Table 4.

Table 3 Levels of the target ship

\begin{tabular}{|c|c|c|c|c|c|c|c|}
\hline Design parameter & $h$ & $t_{O}$ & $t_{I}$ & $t_{D}$ & $t_{E}$ & $N_{I}$ & $C$ \\
\hline Level & -1 & -1 & -1 & -1 & -1 & 0 & -1 \\
\hline
\end{tabular}
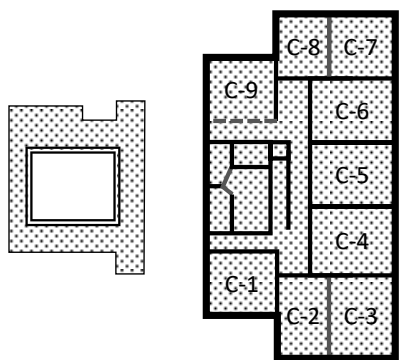

Fig. 6 Joiner plan of $\mathrm{C}$ deck if $C$ is "Separated"

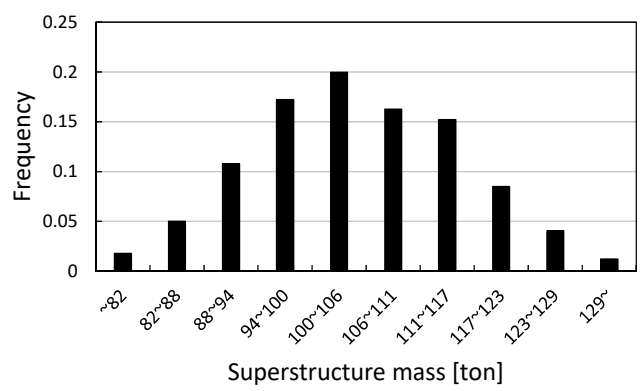

Fig. 7 Frequency distribution of the superstructure mass 


\section{2.3. $3 \mathrm{RS}^{4)}$}

In the design parameters' combination of the calculation points shown in Table 4, noise levels in each frequency and each room were calculated by SEA. Furthermore, noise in any design parameters' combinations were estimated by a linear polynomial using levels of the design parameters as shown in Eq. (9).

$$
y_{i, f}^{\prime}=\mathbf{X}^{\prime} \boldsymbol{\beta}_{i, f}
$$

where $y^{\prime}{ }_{i, f}$ is estimated noise for each room and each frequency, $\mathbf{X}^{\prime}$ is the design parameters to estimate (the values at the first column is 1) and $\boldsymbol{\beta}_{i, f}$ is coefficients for the levels of the design parameters, i.e. RS. $\boldsymbol{\beta}_{i, f}$ is given as Eq. (10).

$$
\boldsymbol{\beta}_{i, f}=\left(\mathbf{X}^{\mathrm{T}} \mathbf{X}\right)^{-1} \mathbf{X}^{\mathrm{T}} \boldsymbol{y}_{i, f}
$$

where $\boldsymbol{y}_{i, f}$ is noise calculated in each calculation point for each room and each frequency, i.e. RSs were established for each room and each frequency respectively.

OA estimated for each room $\left(y_{i, \mathrm{OA}}^{\prime}\right)$ is obtained by the sum of power to estimated noise in each frequency as shown in Eq. (11).

$$
y_{i, \mathrm{OA}}^{\prime}=10 \log _{10}\left(10^{y_{i, 63 \mathrm{~Hz}}^{\prime} / 10}+\ldots+10^{y_{i, 10 \mathrm{kHz}}^{\prime} / 10}\right)
$$

\section{2. 3. 4 Optimal solution}

The relationship between the total probability and the superstructure mass increment in all design parameters' combinations is shown in Fig. 8. The total probability and the superstructure mass increment are positively correlated, and in general, these relationship can be regarded as trade-off.

The relationship between the design parameters' levels, the superstructure mass increment $(\mathrm{dM})$ and the total probability estimated by RS in the optimal solution for each $\mathrm{dM}$ criterion is shown in Table 5. In this paper, it was decided that $\mathrm{dM}$ criterion is 10 ton taking into account of ship designers' perspective. Therefore, in the interior design phase, optimization of the noise control measures was carried out to the hull structure of the optimal solution at the baseline design phase in the case where $\mathrm{dM}$ criterion is 10 ton. In the optimal solution at the baseline design phase, noise levels were analyzed using SEA. The result is shown in Table 6 . The total probability of the optimal solution based on noise calculated using SEA is 0.44 . Since the total probability of the original model is 0.33 , the total probability was improved by $33 \%$ by increasing the superstructure mass by $11 \%$.

\section{2. 3. 5 Efficiency of each design parameter around the original model}

In this paper, models around the original model means models of which only one design parameter is changed from that of the original model. The relationship between the total probability and $\mathrm{dM}$ of the models around the original model, and those average inclinations (total probability increment over $\mathrm{dM}$ ) are shown in Fig. 9. In Fig. 9, the total probability is not based on calculated noise, but on estimated noise. The design parameter, of which average inclination is high, can be regarded as high efficient in this optimization. As shown in Fig. 9, $h$ (deck height) is the design parameter of which average inclination is highest, and $t_{D}$ (deck thickness) and to (outer wall thickness) are second and third highest. $N_{I}$ (the number of steel walls) is the design parameter of which average inclination is lowest, and the value is minus.
As shown in Table 5, regarding $h$ of which average inclination is highest, high level was most preferentially selected. Regarding $t_{D}$ and $t_{O}$ of which average inclinations are second and third highest, high levels were preferentially selected. On the other hand, all levels of $N_{I}$ of which average inclination is minus were -1 . Therefore, the result shown in Fig. 9 corresponds to Table 5 .

Table 4 Calculation points determined using D-optimal design

\begin{tabular}{|c|c|c|c|c|c|c|c|}
\hline \multirow{2}{*}{ ID } & \multicolumn{7}{|c|}{ Level } \\
\cline { 2 - 8 } & $h$ & $t_{O}$ & $t_{I}$ & $t_{D}$ & $t_{E}$ & $N_{I}$ & $C$ \\
\hline \hline EX.01 & -1 & -1 & -1 & -1 & -1 & 1 & -1 \\
\hline EX.02 & -1 & -1 & -1 & 1 & -1 & 1 & 1 \\
\hline EX.03 & -1 & -1 & 1 & -1 & -1 & -1 & -1 \\
\hline EX.04 & -1 & -1 & 1 & 1 & 1 & 1 & -1 \\
\hline EX.05 & -1 & 0 & -1 & 1 & 1 & -1 & 1 \\
\hline EX.06 & -1 & 1 & -1 & 0 & 1 & 1 & -1 \\
\hline EX.07 & -1 & 1 & 1 & -1 & -1 & 1 & 1 \\
\hline EX.08 & -1 & 1 & 1 & 1 & -1 & -1 & -1 \\
\hline EX.09 & 1 & -1 & -1 & -1 & -1 & -1 & 1 \\
\hline EX.10 & 1 & -1 & -1 & -1 & 1 & -1 & -1 \\
\hline EX.11 & 1 & -1 & 1 & 1 & -1 & 1 & 1 \\
\hline EX.12 & 1 & -1 & 1 & 1 & 0 & 1 & -1 \\
\hline EX.13 & 1 & -1 & 1 & 1 & 1 & -1 & 1 \\
\hline EX.14 & 1 & 1 & -1 & 1 & -1 & -1 & -1 \\
\hline EX.15 & 1 & 1 & -1 & 1 & -1 & 1 & -1 \\
\hline EX.16 & 1 & 1 & 1 & -1 & 1 & 1 & 1 \\
\hline
\end{tabular}

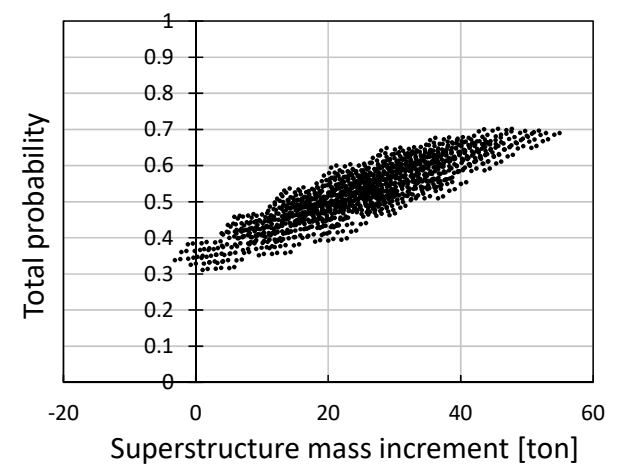

Fig. 8 Relationship between the total probability and the

\begin{tabular}{|c|c|c|c|c|c|c|c|}
\hline \multicolumn{2}{|c|}{$\begin{array}{c}\mathrm{dM} \text { criterion } \\
\text { [ton] }\end{array}$} & 0 & 10 & 20 & 30 & 40 & No limit \\
\hline \multirow{7}{*}{ 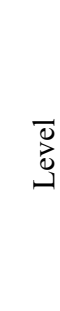 } & $h$ & 1 & 1 & 0 & 1 & 1 & 1 \\
\hline & to & -1 & -1 & 0 & 1 & 1 & 1 \\
\hline & $t_{I}$ & -1 & -1 & -1 & -1 & 0 & 1 \\
\hline & $t_{D}$ & -1 & 0 & 1 & 1 & 1 & 1 \\
\hline & $t_{E}$ & -1 & 0 & -1 & -1 & 0 & 1 \\
\hline & $N_{I}$ & -1 & -1 & -1 & -1 & -1 & -1 \\
\hline & $C$ & -1 & -1 & 1 & -1 & -1 & -1 \\
\hline \multicolumn{2}{|c|}{$\mathrm{dM}$ [ton] } & -0.5 & 8.7 & 19.3 & 28.8 & 38.2 & 47.7 \\
\hline \multicolumn{2}{|c|}{$\begin{array}{c}\text { Total } \\
\text { probability }\end{array}$} & 0.38 & 0.47 & 0.57 & 0.65 & 0.68 & 0.70 \\
\hline
\end{tabular}
superstructure mass increment

Table 5 Optimal solution for each $\mathrm{dM}$ criterion 
The noise levels in the accommodation space can be reduced efficiently by means of increasing deck height, deck thickness and outer wall thickness preferentially in this ship model at least. In this regard, however, it should be noted that the tendency cannot be always found in all ships because it depends on individual hull structures. Furthermore, it should also be noted that $h$ is not the most effective, but the most effective per unit mass increment. As shown in Fig. 8, the inclination of $h$ is highest but the total probabilities when level of $t_{D}, t_{O}$ or $t_{I}$ is 1 are higher than the total probability when $h$ is 1 because of a design range limitation of $h$.

\section{3 Interior design phase}

\section{3. 1 Design parameters}

Although no noise control measure is applied to the target ship, appropriate noise control measures are useful in order to reduce noise levels in the accommodation space in general. Having considered an acoustical ceiling panel and a floating floor, which are widely used as noise control measures, the adoption of these noise control measures in each room were regarded as the design parameters at the interior design phase. In addition, anti-vibration mounts for generator set were also considered and these adoption was regarded as one of the design parameters. These noise control measures were modeled in SEA, and these effect were evaluated.

\section{3. 1. 1 Modeling of acoustical ceiling panel}

The acoustical ceiling panel is shown in Fig. 10. It is the special porous panel for ceiling, and in general, it is applied to increase sound absorption coefficient in the room.

Table 6 Noise at the optimal solution of the baseline design phase

\begin{tabular}{|c|c|c|c|c|}
\hline $\begin{array}{c}\text { Room } \\
\text { name }\end{array}$ & $\begin{array}{c}\text { Criterion } \\
{[\mathrm{dB}]}\end{array}$ & $\begin{array}{c}\text { Calculated noise } \\
\text { (Difference from } \\
\text { the original) [dB] }\end{array}$ & $\begin{array}{c}\text { Estimated } \\
\text { noise [dB] }\end{array}$ & $\begin{array}{c}\text { Partial } \\
\text { probability }\end{array}$ \\
\hline \hline C-1 & 90 & $50.4(-0.1)$ & 50.4 & 1.00 \\
\hline C-2 & 60 & $46.1(+0.1)$ & 46.1 & 1.00 \\
\hline C-3 & 60 & $45.5(-0.2)$ & 45.6 & 1.00 \\
\hline C-4 & 60 & $47.0(-0.4)$ & 47.4 & 1.00 \\
\hline C-5 & 60 & $47.0(-0.4)$ & 47.4 & 1.00 \\
\hline C-6 & 60 & $48.1(-0.2)$ & 48.5 & 1.00 \\
\hline C-7 & 60 & $47.3(-0.1)$ & 50.3 & 1.00 \\
\hline C-8 & 60 & $50.5(+0.3)$ & 47.5 & 1.00 \\
\hline C-9 & 60 & $52.0(-0.2)$ & 52.5 & 1.00 \\
\hline B-1 & 60 & $55.2(-0.2)$ & 55.4 & 1.00 \\
\hline B-2 & 60 & $53.9(-0.1)$ & 54.1 & 1.00 \\
\hline B-3 & 60 & $52.1(-0.7)$ & 52.8 & 1.00 \\
\hline B-4 & 60 & $53.3(-0.3)$ & 53.3 & 1.00 \\
\hline B-5 & 60 & $53.2(-0.3)$ & 53.2 & 1.00 \\
\hline B-6 & 60 & $54.0(-0.1)$ & 53.9 & 1.00 \\
\hline B-7 & 60 & $53.2(-0.7)$ & 57.0 & 1.00 \\
\hline B-8 & 60 & $56.9(-0.1)$ & 53.8 & 0.98 \\
\hline B-9 & 60 & $58.6(-0.2)$ & 58.8 & 0.83 \\
\hline P-1 & 65 & $64.9(-0.4)$ & 65.3 & 0.53 \\
\hline P-2 & 65 & $57.9(-0.8)$ & 58.6 & 1.00 \\
\hline P-3 & 65 & $60.5(-0.2)$ & 60.7 & 1.00 \\
\hline & & & Total $)$ & 0.44 \\
\hline
\end{tabular}

In this paper, the sound absorption coefficient was increased on the basis of measurement experience of other ships, when modeling the acoustical ceiling panel. The sound absorption coefficients are shown in Fig. 11.

\section{3. 1 . 2 Modeling for floating floor}

The floating floor is shown in Fig. 12. The floating floor is consisted of materials, which is expected to reduce vibration energy input from the deck, such as a rock wool, and it is applied on the deck.

In this paper, Noise Control Treatments (NCTs) between acoustic elements of room to be applied and structural elements of its deck were changed, when modeling the floating floor. If the floating floor is not applied, the NCT between the room and its deck was only considered deck composition of $9 \mathrm{~mm}$, and vibration energy of the deck transmits to the room through the deck composition. On the other hand, if the floating floor is applied, the NCT consists of rock wool of $50 \mathrm{~mm}$, steel plate of $3.2 \mathrm{~mm}$ and deck composition of $9 \mathrm{~mm}$ from the deck side as shown in Fig. 13.

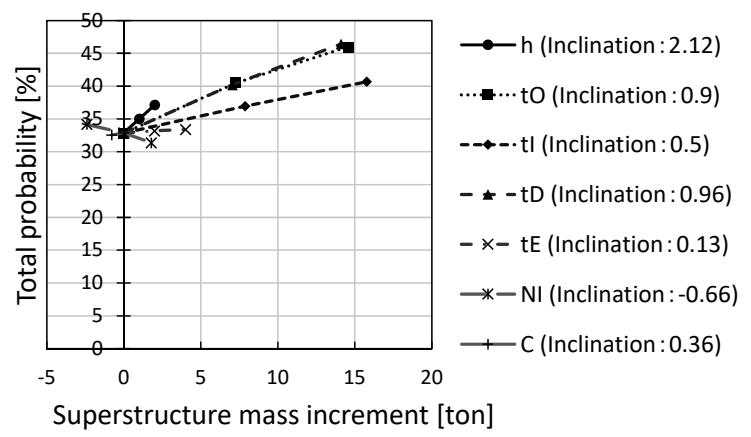

Fig. 9 Relationship between the total probability and the superstructure mass increment around the original model

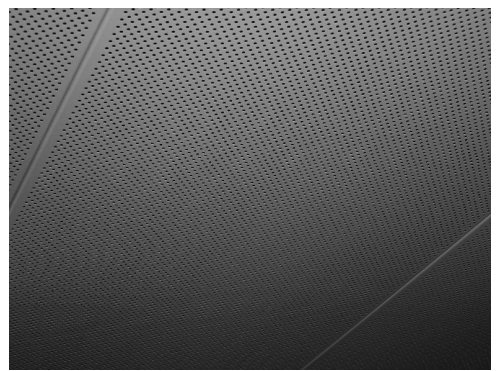

Fig. 10 Acoustic ceiling panel

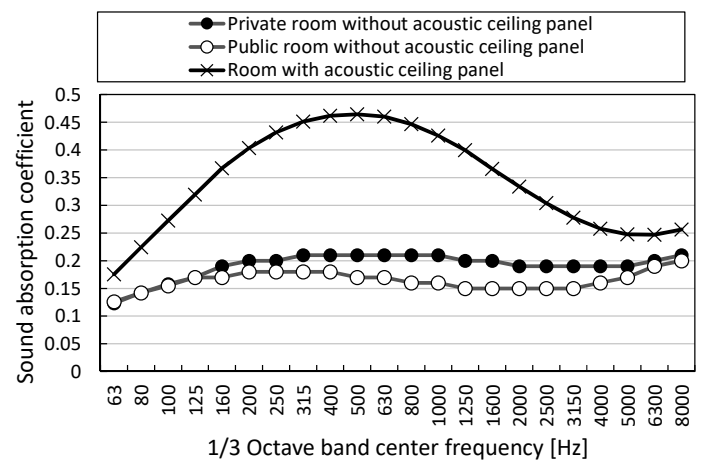

Fig. 11 Impact of the acoustic ceiling panel on sound absorption coefficient 


\section{3. 1. 3 Modeling for anti-vibration mounts for generator set}

The anti-vibration mounts for generator set are shown in Fig. 14. As shown in Fig. 14, the anti-vibration mounts are applied between a common bed for generator set and foundation for generator set. In general, the anti-vibration mounts are applied in order to reduce vibration energy from the generator engine.

As mentioned in paragraph 2.2.2, vibration measurements are used in the SEA model as a boundary condition. Therefore, in this paper, vibration level of the boundary condition at the structural elements where the generator set is located was decreased when modeling the anti-vibration mounts. In this study, it was assumed that the vibration velocity levels are reduced by $10 \mathrm{~dB}$ for each frequency by means of applying the anti-vibration mounts. The vibration velocity levels is shown in Fig. 15.

\section{3. 2 Objective function}

The noise control measures are expected to reduce noise levels even though its mass increase is slight compared with hull structure change at the baseline design. However, the noise control measures need corresponding costs. Therefore, at the interior design phase, the authors carried out a multi-objective optimization of which objective function is the total noise control measures' cost (total cost) as well as the total probability. Each noise control measure's cost is shown in Table 7.

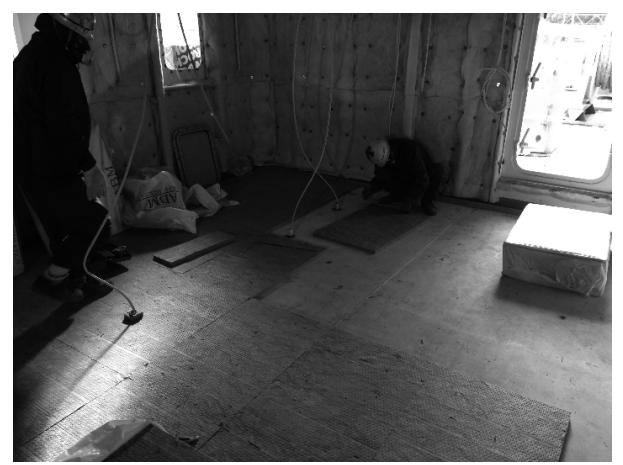

Fig. 12 Floating floor

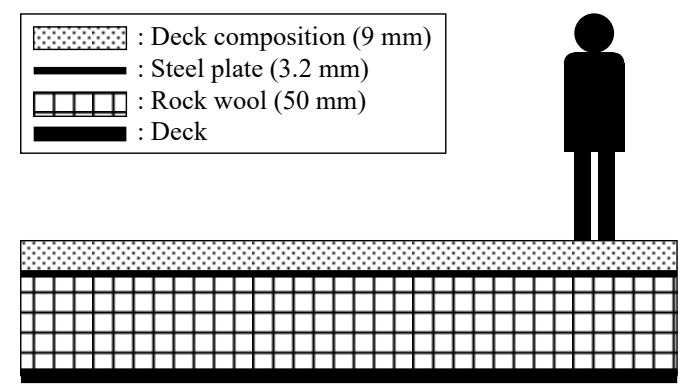

Fig. 13 Floating floor constitution in this SEA model

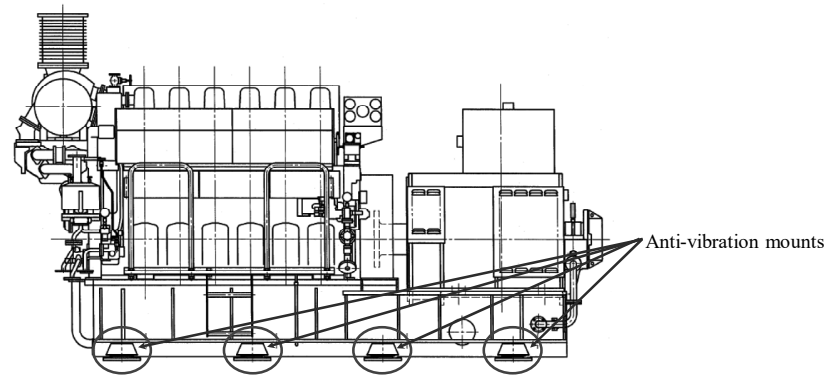

Fig. 14 Anti-vibration mounts for generator set.

\section{3. 3 Optimal solution searching method}

Considering the adoptions of the acoustical ceiling panel and floating floor for each room respectively, the number of the combination is $4^{21} \times 2$, i.e. $8.8 \times 10^{12}$. In this regard, it is difficult to model and calculate using SEA in all combinations due to such a huge number. In addition, on the basis of experience of noise measurement and SEA calculation, it can be assumed that these noise control measures affect only rooms to be applied. Therefore, only eight SEA models (i.e. combination number of presence or absence of three noise control measure) were developed as shown in Table 8, and noise levels in each room and each design parameter referred to the corresponding results in Table 8. For example, regarding a model in the case where the anti-vibration mounts are not applied to the generator set and the acoustic ceiling panel and the floating floor are applied to $\mathrm{C}-1$ but not to $\mathrm{C}-2$, the noise levels of $\mathrm{C}-1$ and $\mathrm{C}-2$ referred to the results of No. 7 and No. 1 models in Table 8 respectively. Since the number of all combinations of the design parameters is remarkably huge, it is difficult to search optimal solution among all combinations even though noise levels are given. Therefore, the authors carried out a suboptimization which divides the rooms into three groups. In this suboptimization, the Pareto optimal solutions (i.e. combinations of design parameter when no solution is superior than them in all objective function) for each group were searched by means of the full search, after that, optimal combinations of Pareto optimal solutions in each group were searched by means of the full search. Thereby, calculation cost was reduced from the order of $10^{12}$ to $10^{4}$. Since the partial probability and cost of one room are independent on those of other rooms, the Pareto optimal solution obtained by means of this suboptimization is equal to the optimal solution obtained without the suboptimization.

\section{3. 4 Pareto optimal solution}

The relationship between the total probability and the total cost in Pareto optimal solution is shown in Fig. 16. Fig. 16(b) is a figure in which Fig. 16(a) is in the range of 0 to 1,500,000 yen. The total probability increases until the total cost about 100,000 yen, after that, it is almost flat. As shown in Fig. 16, the relationship between the total probability and the total cost in the optimal solution can be separated into some modes. Confirming levels in each optimal solution, a tendency of arrangement of noise control measures for each mode was found as shown in Table 9. For example, in mode II, the acoustic ceiling panel and the floating floor are not applied to P-1 and only the acoustic ceiling panel is applied to B-9. In Table 9, there is no mode applied anti-vibration mounts except for mode VII. As shown in Table 6, the room of which partial probability is lowest is P-1 and second is B-9. Therefore, the modes shown in Fig. 16 and Table 9 are classified by noise control measures of these rooms of which partial probabilities are low. This classification is in line with an instinctive countermeasure to apply noise control measures preferentially to rooms of which partial probability is low.

In this study, the impact of the anti-vibration mounts for generator set on the total probability was less than that of other noise control measures. However, it should be noted that this tendency depends on individual hull structures. If main noise source is vibration of the generator engine and partial probabilities of many rooms are low, it is expected that the total probability significantly increases by means of applying it. 


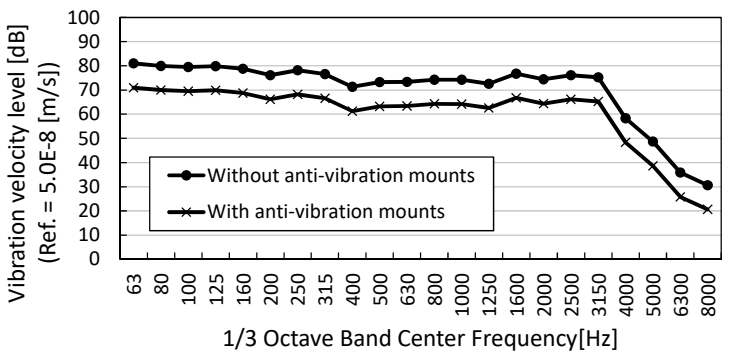

Fig. 15 Impact of the anti-vibration mounts on the vibration velocity levels

Table 7 Noise control measure's cost

\begin{tabular}{|l|rr|}
\hline \multicolumn{1}{|c|}{ Noise control measure } & \multicolumn{1}{|c|}{ Cost } \\
\hline \hline Acoustical ceiling panel & $2,000 \quad$ yen $/ \mathrm{m}^{2}$ \\
\hline Floating floor & $40,000 \quad$ yen $/ \mathrm{m}^{2}$ \\
\hline Anti-vibration mounts for generator set & $2,000,000 \quad$ yen \\
\hline
\end{tabular}

Table 8 Calculation points in SEA at the interior design phase

\begin{tabular}{|c|c|c|c|}
\hline \multicolumn{1}{|c|}{ ID } & $\begin{array}{c}\text { Acoustic ceiling } \\
\text { panel }\end{array}$ & $\begin{array}{c}\text { Floating } \\
\text { floor }\end{array}$ & $\begin{array}{c}\text { Anti-vibration mounts } \\
\text { for generator set }\end{array}$ \\
\hline \hline No. 1 & $\mathrm{N}$ & $\mathrm{N}$ & Not applied \\
\hline No. 2 & $\mathrm{N}$ & $\mathrm{N}$ & Applied \\
\hline No. 3 & $\mathrm{N}$ & $\mathrm{A}$ & Not applied \\
\hline No. 4 & $\mathrm{N}$ & $\mathrm{A}$ & Applied \\
\hline No. 5 & $\mathrm{A}$ & $\mathrm{N}$ & Not applied \\
\hline No.6 & $\mathrm{A}$ & $\mathrm{N}$ & Applied \\
\hline No. 7 & $\mathrm{A}$ & $\mathrm{A}$ & Not applied \\
\hline No. 8 & $\mathrm{A}$ & $\mathrm{A}$ & Applied \\
\hline
\end{tabular}

A: Applied to all rooms

$\mathrm{N}$ : Not applied to all rooms

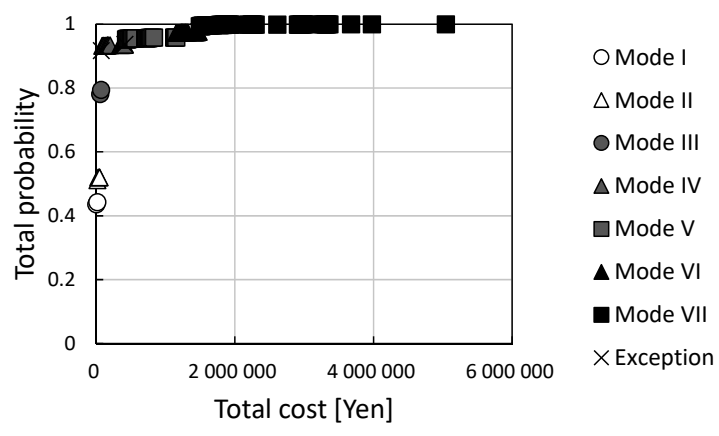

(a) Total cost from 0 to $6,000,000$ yen

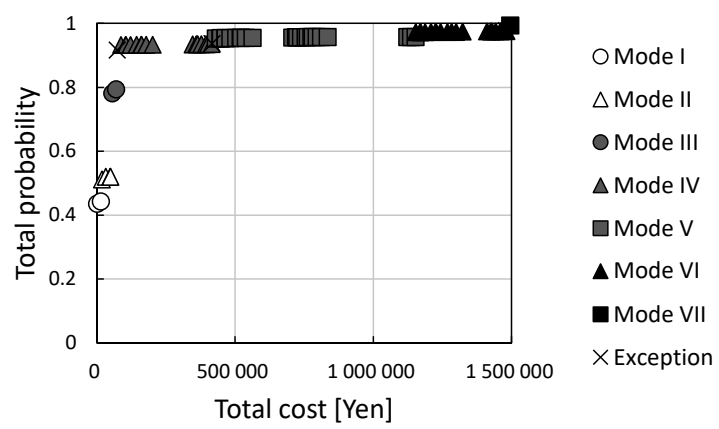

(b) Total cost from 0 to $1,500,000$ yen

Fig. 16 Relationship between the total cost and the total probability at the optimal solution in the interior design phase

\section{Conclusions}

For a certain oil tanker of 6,500 kiloliters actually constructed by a shipyard, its noise levels were measured and calculated using its SEA models. Furthermore, the optimization of the hull structure and noise control measures were carried out.

In the baseline design phase, the authors carried out the optimization, of which design parameters are the hull structure arrangements, of which constraint is the superstructure mass increment and of which objective function is the total probability. Furthermore, it was found that noise levels can be efficiently reduced by means of increasing deck height, deck thickness and outer wall thickness preferentially.

In the interior design phase, on the basis of the result of the optimization at the baseline design phase, the multi-objective optimization was carried out. In this regard, its design parameters are the adoptions of the noise control measures, i.e. the acoustic ceiling panel and the floating floor for each room and anti-vibration mounts for generator set, and its objective functions are the total probability and cost. In interior design phase, it was found that the optimal solution can be separated into some modes and these modes correspond to the adoptions of noise control measures for rooms of which partial probabilities are low at the baseline design phase.

Consequently, hull structure arrangements and adoptions of the noise control measures were optimized efficiently through proposed optimization methods for each design phase. Additionally, it should be also noted that the proposed optimization methods can be applied for general ships without limiting only to the target ship.

In order to confirm general tendencies, it is needed for other ships to carry out similar study. In addition, change of gravity center and of resonance frequency by changing hull structures should be also considered as constraint in the future. Furthermore, since calculation results depend on individual hull structures, it should be noted that there is no generality in the results of efficiency for each noise countermeasure and verification for each individual hull structure is needed.

\section{Acknowledgments}

This study was carried out under "Investigation for design of best ship for noise $(6,500 \mathrm{kl}$ tanker)" by Japan Railway Construction, Transport and Technology Agency (JRTT) in 2016 and 2017. The authors are grateful to the persons concerned.

Table 9 Definition of mode in Fig. 15.

\begin{tabular}{|c|c||c|c|c|}
\hline \multicolumn{2}{|c||}{} & \multicolumn{3}{c|}{ P-1 } \\
\cline { 2 - 5 } \multicolumn{2}{|c|}{} & A & B & C \\
\hline \hline \multirow{3}{*}{ B-9 } & A & Mode I & Mode III & \\
\cline { 2 - 5 } & B & Mode II & Mode IV & Mode VI \\
\cline { 2 - 5 } & C & & Mode V & Mode VII \\
\hline
\end{tabular}

A: Acoustic ceiling panel and floating floor are not applied.

B: Only acoustic ceiling panel is applied.

C: Acoustic ceiling panel and floating floor are applied. 


\section{References}

1) CODE ON NOISE LEVELS ON BOARD SHIPS, International Maritime Organization (IMO), 2012.

2) VAONE, https://www.esi-group.com

3) RSMaker, http://todoroki.arrow.jp/ssoft/RSMkaisetsu.pdf

4) Akira Todoroki, Introduction to Optimal Design for Nonlinear Problem with Response Surface Methodology, 1999, Seminar of Japan Society of Mechanical Engineer. 